\title{
IMPLICAÇÕES ONTOLÓGICAS DAS REDES SOCIAIS: ASPECTOS DA ALIENAÇÃO CONTEMPORÂNEA
}

\author{
Recebido em 12/04/2021, aprovado em 26/05/2021 \\ $10.30612 /$ mvt.v8i14.14470 \\ José Wilson Assis Neves Júnior ${ }^{1}$
}

RESUMO: O presente artigo tem por intuito problematizar os impactos decorrentes do atual estágio de desenvolvimento das redes sociais de comunicação Facebook e o Instagram no âmbito social do ser, abordando o objeto a partir da percepção ontológica do materialismo histórico-dialético proposta por George Lukács. No que tange ao Facebook, indicou-se tanto o seu potencial de articulação política e social que, em determinados casos, viabilizaria transformaçóes efetivas nas relaçóes de dominação quanto a sua apropriação como mecanismo de isolamento do ser em relação à totalidade da vida social, contribuindo para o aprofundamento das tendências alienantes. No caso do Instagram, por sua vez, evidenciou-se a sua consolidação enquanto um espaço digital que possibilita a completa distorção da realidade concreta do sujeito singular, potencializando não só a reprodução de uma lógica de resignação do ser social em relação às pressuposições de uma realidade de ideologia única, como também a ascensão de espaços de fuga dos problemas materiais, que aprofundam o caráter alienante do ser social na conjuntura contemporânea.

Palavras-chave: Facebook.Instagram.Alienação.

\section{ONTOLOGICAL IMPLICATIONS OF SOCIAL MEDIA: ASPECTS OF CONTEMPORARY ALIENATION}

\begin{abstract}
This paper problematizes the impacts of contemporary development stages of social medias Facebook and Instagram to the social sphere of the Being, approaching the object an ontological perspective of historical dialectical materialism proposed by George Lukács. Regarding Facebook, the potential of political and social mobilization in some cases enables real transformations at domination relations as well as it's appropriation as an mechanism of isolation of the Being from the totality of social life, contributing to deepening the alienations tendencies. In the case of Instagram, evince shows the consolidation of a digital space that makes possible the complete distortion of the singular subject from the concrete reality, potentiating the reproduction of a
\end{abstract}

$1 \quad$ Doutor em Ciências Sociais pela Universidade Estadual Paulista (Unesp/Marília). Mestre e bacharel em Ciências Sociais pela Universidade Estadual de Londrina (UEL). Pesquisador vinculado ao Grupo de Pesquisa sobre Pensamento Político Brasileiro e Latino-Americano (Unesp/Marília) e ao Laboratório de Estudos sobre Religiōes e Religiosidades (LERR-UEL). E-mail: nevesjr1991@gmail.com. 
resignation logic on the social Being in relation to reality assumption of the unique ideology, as well as the rising of scape spaces from material problems that deepens the alienation aspects of the social Being on the contemporary conjuncture.

Keywords: Facebook. Instagram.Alienation.

\section{IMPLICACIONES ONTOLÓGICAS DE LAS REDES SOCIALES: ASPECTOS DE LA ALIENACIÓN CONTEMPORÁNEA}

RESUMEN: El propósito de este artículo es problematizar los impactos derivados de la actual etapa de desarrollo de las redes de comunicación social Facebook e Instagram en el ámbito social del ser, abordado el objeto desde la percepción ontológica del materialismo histórico-dialéctico propuesto por George Lukács. Con respecto a Facebook, se señaló tanto su potencial de articulación política como social, lo que, en ciertos casos, permitiría transformaciones efectivas en las relaciones de dominación y su apropiación como mecanismo de aislamiento del ser con relación a la totalidad de la vida social, contribuyendo a la profundización de tendencias alienantes. En el caso de Instagram, en cambio, se evidenció su consolidación como un espacio digital que permite distorsionar por completo la realidad concreta del sujeto singular, potenciando la reproducción de una lógica de resignación del ser social en relación a los presupuestos de una realidad de ideología única y también el surgimiento de espacios de evasión de los problemas materiales que profundizan el carácter alienante del ser social en la coyuntura contemporánea.

Palabras Clave: Facebook. Instagram. Alienación.

\section{INTRODUÇÃO}

As primeiras décadas do século XXI foram marcadas pela difusão, em distintos níveis sociais, de uma forte crença no potencial democratizante que as novas tecnologias de informaçóes, em especial aquelas decorrentes do surgimento e popularização da internet, ofereceriam para os mais distintos países. Manuel Castells (2017) classifica esta etapa conjuntural como "sociedade em rede", evidenciando o caráter dinâmico que perpassa a transmissão de informaçôes em uma rede ampla de indivíduos interconectados, alheios aos parâmetros geográfico-espaciais que limitavam as comunicaçóes entre sujeitos sociais, inclusive no passado recente.

Assim, revestido pelo manto da pressuposta marcha democratizante internacional, o desenvolvimento acelerado das tecnologias de comunicação virtuais possíveis de disponibilizaçáo à sociedade civil, cujas redes sociais são o estágio contemporâneo mais avançado do processo no âmbito de acesso da sociedade civil, obteve massivo e rápido êxito na aceitaçáo das condiçóes que os sujeitos singulares necessitam para adentrar neste universo.

Entretanto, o caráter destas tecnologias de comunicação digitais e as imprecisôes quanto às múltiplas possibilidades de impactos que podem advir do seu desenvolvimento em realidades particulares é, ainda, uma relevante demanda de estudos para o campo das ciências sociais, evidenciando que "é precisamente esse grau de incerteza que impôe a necessidade de uma reflexão pragmática e normativaorientada para possíveis impactos da internet, positivos e negativos, sobre a democratização da sociedade contemporânea” (EISENBERG, 2003, p. 492). 
Tendo em vista estademanda analítica, este trabalho visa problematizar as implicaçóes de determinadas ferramentas de interaçáo entre sujeitos singulares no âmbito da totalidade do ser social, partindo de uma abordagem abstrata e qualitativa das formas de interação que permeiam a inserção dos sujeitos singulares nas redes sociais Facebook e Instagram, buscando, assim, apreender as implicaçôes ontológicas deste fenômeno (positivas ou negativas).

Para tanto, apropriou-se como horizonte teórico-metodológico a perspectiva de análise ontológica do materialismo histórico e dialético de matriz lukácsiana, o que demanda reconhecer as formas dinâmicas assumidas pelos distintos e múltiplos componentes da vida social. Assim, apreende-se as redes sociais e as formas como os sujeitos sociais as apropriam como produtos e produtores das particularidades que caracterizam a inserção das diversas sociedades no complexo de complexos da produção internacional de capital (LUKÁCS, 2018a; 2018b).

Visando contribuir qualitativamente para esta temática de análise e não objetivando esgotar as discussóes acerca do problema, o presente trabalho encontra-se dividido em três partes. Na primeira são traçadas conceituaçôes básicas a respeito do complexo ideológico que perpassa a interpretação ontológica de Lukács (2018a; 2018b) sobre a vida social. Em seguida, aborda-se o caso dual que perpassa o surgimento e difusão do Facebook enquanto ferramenta de comunicação virtual contemporânea. Por fim, atenta-se às particularidades que caracterizam o Instagram como uma das ferramentas com maior potencial de aprofundamento das tendências alienantes ${ }^{2}$ do ser social.

\section{VIDA SOCIAL E ALIENAÇÃO}

O trabalho é apreendido por Lukács (2018a; 2018b) como categoria fundante da vida social parte do pressuposto que a partir da divisão social do trabalho os sujeitos sociais organizam suas relaçóes, sendo justamente esta capacidade de transformação metabólica da natureza (teleológicaprimária) o elemento que caracteriza e diferencia a humanidade. Em decorrência desta peculiaridade, os sujeitos singulares vislumbram a possibilidade de colocar em prática projetos de desenvolvimento da sociedade que viabilizem as transformaçóes da natureza que favoreçam determinados tipos de desenvolvimento humano, esbarrando-se, com isto, na necessidade de criar sistemas de pensamento que induzam os demais sujeitos singulares a adequarem-se aos modelos de divisão do trabalho que caracterizam estas distintas vias de desenvolvimento humano (pôr teleológico secundário). É necessário considerar que:

[...] o ser social, em sua estrutura ontológica fundamental, representa algo unitário: seus "elementos" últimos são as posiçôes teleológicas dos seres humanos que, em sua qualidade ontológica fundamental, o interior e no exterior da esfera econômica, não exibem nenhuma marca distintiva por princípio diferente. Naturalmente, essa constataçẫo não significa nenhuma homogeneidade dessas posiçóes. Em outras conexóes foi seguidamente apontado que posições que são imediatamente dirigidas ao metabolismo entre sociedade e natureza, essencialmente se diferenciam, tanto subjetivamente quanto objetivamente, daquelas cuja intenção direta é a alteração da consciência de outros seres humanos; também estas podem mostrar diferenças qualitativas, tudo depende de quão amplas são as mediaçóes das visadas alterações

\footnotetext{
2 Em concordância com Lessa (2018), a pesquisa deu preferência à utilização do termo "alienação" em lugar do usual "estranhamento", tendo em vista que, apesar de perpassar o fenômeno da alienação, o estranhamento náo corresponde à sua totalidade, considerando que este implica a existência de um determinado nível de consciência do sujeito singular acerca dos problemas alienantes que permeiam a determinada atividade em questão.
} 
na consciência com o problema direto da reprodução dos seres humanos, e qual é o conteúdo dessas alteraçóes (LUKÁCS, 2018b, p. 337).

Disto decorre a necessidade de apreender as particularidades das vias de desenvolvimento ${ }^{3}$ das sociedades,assim como as múltiplas configuraçóes que perpassam a conjuntura que se ambiciona apreender. As formas como os sujeitos singulares se organizam no âmbito social é dinâmica e complexa, perpassando tanto a relação que se estabelece com o modo de produção vigente, quanto com as construçôes de ideias e instituiçôes necessárias para viabilizar sua reprodução na vida social. Este fenômeno complexo provém justamente do fato de que:

O concreto é concreto porque é a síntese de múltiplas determinaçóes, isto é, unidade do diverso. Por isso, o concreto aparece no pensamento como o processo de síntese, como resultado, não como ponto de partida, embora seja o verdadeiro ponto de partida e, portanto, o ponto de partida também da intuição e da representação (MARX, 2008, p. 258-259).

Constata-se, pois, que a forma dinâmica que se materializa na vida social decorre, em grande medida, das relaçôes que se estabelecem entre o complexo de produção (relação de transformação da natureza pela capacidade de previa ideação da humanidade) e o complexo ideológico (mediaçóes postuladas para dirigir as interaçóes entre os sujeitos singulares no cotidiano). Estes dois complexos devem ser entendidos tanto como produtos quanto reprodutores um do outro - as distintas formas ideológicas são construtos do pensamento humano, condicionadas e limitadas pelo estágio de desenvolvimento que ambicionam reproduzir ou superar, da mesma forma como as capacidades de transformação da natureza são limitadas e determinadas pela capacidade do gênero humano em um dado estágio de desenvolvimento (VAISMAN, 2010).

Esbarra-se, assim, com a necessidade de conceituar o que se entende, neste trabalho, como "ideologia". Apesar de evidenciar a forma como a(s) ideologia(s) de uma conjuntura perpassa(m) de modo amplo todas as formas de pensar e agir dos sujeitos singulares e, especialmente, se enraízam nas instituiçôes construídas para a manutenção e reprodução da ordem (religião, política, direito, entre outras), Lukács (2018b) traça um criterioso crivo para a classificação de uma forma de pensar como sendo ou não ideologia. Para o filósofo húngaro:

ideologia é antes de tudo, aquela forma de elaboração intelectual da realidade a qual serve para fazer consciente e capaz de ação a práxis social dos seres humanos [...] Pois, em um modo disso inseparável, a ideologia é um meio das lutas sociais, que caracteriza toda sociedade (LUKÁCS, 2018b, p. 398-399).

É relevante, neste ponto, atentar-se à percepção da ideologia (enquanto posicionamento teleológico secundário) como elemento intrínseco do antagonismo de classes. As diferentes formas que esta construção reflexiva da humanidade pode assumir nas mais diversas e múltiplas conjunturas permeiam, portanto, um processo de lutas entre dominantes e dominados. É importante ressaltar

3 As vias de desenvolvimento sáo caracterizadas por projetos políticos e econômicos de longo prazo que perpassam os objetivos de transformaçáo sociais, políticos, econômicos e culturais que adequam a mencionada sociedade à um determinado modelo de produção, interna e externa à comunidade (LUKÁCS, 1970). 
que a situação de dominante viabiliza a construção e apropriação de instrumentos mais sofisticados para a difusáo do consenso em prol de determinada concepçáo de mundo (que pode se limitar ou fundamentar-se na ideologia vigente). ${ }^{4}$

É justamente dentro deste imbricado complexo ideológico, muito característico das sociedades modernas, que se desenvolve e se aperfeiçoa a alienação - componente essencial para a manutençáo e reprodução de uma ordem de dominação nos parâmetros capitalistas de desenvolvimento. Neste contexto, não se pode deixar de explicitar que:

[...] consideramos a alienação como um fenômeno exclusivamente histórico-social, que emerge em determinados níveis do desenvolvimento existente, tomando desde então formas historicamente sempre diferentes, sempre mais incisivas. Sua qualidade, portanto, nada tem a ver com uma condition humaine geral, muito menos que ela possuiria uma generalidade cósmica (LUKÁCS, 2018b, p. 501).

A alienação, deste modo, não pode ser tomada enquanto um fenômeno estático cuja superação dar-se-ia pelo mero acúmulo de conhecimento crítico sobre determinados aspectos que a perpassam. Muito pelo contrário, a alienação também permeia a imbricada teia das transformaçóes dinâmicas que caracterizam o desenvolvimento das sociedades humanas e, por conseguinte, das configuraçóes que o antagonismo de classes assume em determinadas conjunturas. Isto, contudo, não limita o estabelecimento de determinados princípios que viabilizam uma apreensão abstrata das formas que o fenômeno pode assumir na vida social cotidiana. Por exemplo, é possível aferir que:

[...] primeiro, toda alienação é um fenômeno fundado social-economicamente; sem mudança decisiva na estrutura econômica nenhuma ação individual pode alterar algo essencial nessa base. Segundo, toda alienação, a partir dessa base, é antes de tudo um fenômeno ideológico cujas consequências cercam de muitos lados e solidamente a vida de cada ser humano participante; que sua superaçáo subjetiva apenas como ato do respectivo indivíduo pode ser realizada na prática. É, portanto, absolutamente possível que seres humanos singulares sejam capazes de enxergar através da essência da alienação teoricamente e, todavia, permaneçam alienados em seus modos de vida [...] Terceiro, há no ser social apenas alienaçóes concretas (LUKÁCS, 2018b, p. 551-552).

Estas "regras" para a apreensão da alienação, em verdade, servem mais para elucidar sua complexidade do que traçar estratégias de superá-la - como o próprio trecho transcrito da ontologia lukácsiana indica, reconhecer o caráter alienante de um fenômeno não implica necessariamente o início de um processo de superação. ${ }^{5} \mathrm{O}$ processo de individualização do ser social, assim, constitui etapa crucial para o desenvolvimento e aprofundamento da alienaçáo nas sociedades modernas (LUKÁCS, 2020). Nesse sentido, é importante ressaltar que:

A contradição dialética entre o desenvolvimento da capacidade e o desenvolvimento da personalidade, portanto a alienação, por toda a sua importância, jamais abarca a completa totalidade do ser social dos seres humanos; por outro lado, jamais se deixa (quando muito em desfiguração subjetiva) ser reduzida a uma contraposição abstrata de subjetividade e objetividade, a uma contraposição de ser humano singular e sociedade, de individualidade e socialidade. Não há nenhuma espécie de subjetividade que, nas raízes e determinações mais profundas de seu ser, não 
seja social. A mais simples análise do ser humano, do trabalho e da práxis, mostra isto em um modo irrefutável (LUKÁCS, 2018b, p. 510).

Apesar de Marx (2011) atribuir ênfase ao modo como a alienação típica da sociedade capitalista distorce a relaçáo do sujeito singular com o produto de seu trabalho, fragmentando o conhecimento sobre a totalidade dos processos, compreende-se que suas contribuições servem de base para apreender a complexidade que a alienação pode assumir nas múltiplas configuraçóes da vida social - não deixando de reconhecer que, em última instância, todas as dimensôes da alienação objetivam interferir nas relaçóes de produção e, subsequentemente, de dominação. O caráter essencial da alienação (a função social que desempenha no cotidiano, em termos de análise da ideologia), ${ }^{6}$ reside justamente na incompreensão da totalidade dos processos que permeiam um determinado ato transformador, ou reprodutor, realizado pelos sujeitos singulares no cotidiano. A partir disto, partilha-se do princípio de que:

[...] quanto mais intensamente a alienação se apoderar de toda a vida interior do trabalhador, tanto mais tranquilamente pode funcionar o domínio do grande capital. Portanto, o aparato ideológico do capitalismo, quanto mais desenvolvido, mais intensamente está preparado para fixar solidamente tais formas de alienação nos seres humanos singulares (LUKÁCS, 2018b, p. 544).

É com o final da Segunda Guerra Mundial (1939-1945) e, especialmente, em decorrência da corrida armamentista que se estabeleceu durante o período de Guerra Fria (1945-1991) entre os Estados Unidos da América (EUA) e a União das Repúblicas Socialistas Soviéticas (URSS) que o desenvolvimento tecnológico assumiu uma forma altamente acelerada. É justamente neste contexto da segunda metade do século XX que as tecnologias de comunicação passam a receber grandes incentivos para o seu aprimoramento, concomitantemente com o processo de cooptação para integrar o aparato ideológico das vertentes políticas e econômicas em disputa. Deste modo:

As novas tecnologias de comunicação e informação surgem a partir de 1975 com a fusão das telecomunicaçôes analógica com a informática possibilitando a veiculação, sob um mesmo suporte - o computador -, de diversas formataçóes de mensagens. Esta revolução digital implica, progressivamente, a passagem do mass media (cujos símbolos são televisão, rádio, imprensa, cinema) para as formas individualizadas de produção, difusão e estoque de informação (LEMOS, 2004, p. 68).

Dentro desta proposta de problematização, compreende-se que, no âmbito da conquista ideológica que permeou a disputa da Guerra Fria, a mídia de massa (mass media) se consolidou como uma relevante ferramenta do aparato ideológico, tendo em vista que o objetivo era a conquista de sujeitos singulares para o compartilhamento de uma determinada concepção de mundo. Em outras palavras, enquanto componente do aparato ideológico, a mídia de massa foi apropriada no sentido

6 A análise da ideologia nos parâmetros ontológicos propostos por Georg Lukács pressupóe a elucidação da função social que a mesma desempenha na realidade cotidiana concreta, ao passo que uma ideologia só pode ser concebida como tal quando direciona as açóes de sujeitos singulares a partir de projetos de por vir que se relacionam com as disputas entre classes (CHASIN, 1978; LOVATTO, 2010) - componente do complexo ideológico, a alienação pode, também, ser abordada desta forma. 
de universalizar princípios basilares da ideologia dominante (em níveis nacionais e internacionais, nos mais diversos países), para a consolidação de um consenso relativo que, em longo prazo, viabilizou a construção, em grande parte do globo, do projeto classificado por István Mészáros (2014, p. 13) como "Estado de ideologia única".

Por outro lado, tendo sido relativamente consolidado o consenso da ideologia única,o aprofundamento da alienação do ser social se apresenta como nova estratégia para a manutenção e reprodução da ordem conquistada. O período que sucedeu a Guerra Fria e a pretensa vitória do capitalismo contra o socialismo foi marcado por acelerados processos de individualização dos sujeitos singulares. No mundo da "Pós-Modernidade", os conceitos de verdade se distorcem, se relativizam e as convicçóes do sujeito singular passam a exercer cada vez mais soberania sobre a forma como este age no âmbito social, cada vez mais fragmentado (LIMA, 2019). Inclusive, é relevante considerar que "[...] a alienaçáo é um dos fenômenos sociais mais decididamente centrados no indivíduo" (LUKÁCS, 2018b, p. 507).

Dentro desta etapa particular do desenvolvimento das sociedades contemporâneas, a ascensão e aprimoramento das ferramentas digitais de comunicação passaram a exercer papel fundamental no processo de reproduçấo da ordem. Chega-se, assim, ao debate mais específico sobre as formas assumidas pelas ferramentas do complexo ideológico capitalista, em nível internacional. Destacamse, dentro deste prisma, as redes de comunicaçôes sociais abertas, criadas nas últimas décadas para acesso via internet que possibilitam níveis amplamente ativos de interação entre os sujeitos singulares mediados por mídias sociais, como é o caso do Facebook e Instagram.

Estes espaços virtuais podem ser caracterizados como os mais dinâmicos aparelhos de difusão ideológica já elaborados pelo sistema de produção capitalista, ${ }^{8}$ ao passo que permitem, por um lado, uma relação muito mais dinâmica de disputas e, por outro, obtêm um nível de alcance jamais visto para difusão de elementos do complexo ideológico que favorecem a reprodução da ordem e, por conseguinte, contribuem para o aprofundamento das tendências alienantes do ser social.

\section{A DUALIDADE DO FACEBOOK}

Fundado em 2004, nos Estados Unidos da América, por cinco alunos de Harvard, ${ }^{\circ}$ o Facebook surge com a proposta de consolidação enquanto plataforma de integração entre pessoas, disponibilizando um espaço para publicação de fotos, vídeos e ideias. A rede social rapidamente se tornou um dos maiores fenômenos digitais das duas primeiras décadas do século XXI, ${ }^{10}$ sendo que, de acordo com o relatório de investimentos disponibilizado pela empresa, em abril de 2020, a rede registrou uma média mensal de aproximadamente 2.60 bilhôes de usuários ativos (FACEBOOK INC., 2020).

\footnotetext{
$7 \quad$ Protagonizado pelos EUA, o mencionado projeto do Estado de ideologia única permeia a construção, e difusão, do consenso social da incapacidade de criação de vias de desenvolvimentos alternativas ao modelo capitalista de produção (MÉSZÁROS, 2014), preconizando, assim, um gradual processo de auto-resignação dos sujeitos singulares que contribui para o aprofundamento das tendências alienantes do ser social.

8 O sistema de produçáo capitalista é entendido como um complexo de complexos (MÉSZÁROS, 2014), no qual diferentes vias de desenvolvimento possibilitam um processo de divisão internacional do trabalho que se transforma de modo dinâmico, possibilitando a ascensão e o aperfeiçoamento de distintos modelos de exploração da natureza e da força de trabalho (LUKÀCS, 1970).

$9 \quad$ Mark Zuckerberg, Eduardo Saverin, Andrew McCollum, Dustin Moskovitz e Chris Hughes.

10 Posteriormente, aFacebook Inc. passou a adquirir e incorporar outras redes sociais de comunicação digitais (como Instagram, WhatsApp e outros), tornando-se um dos cinco maiores conglomerados de tecnologia contemporâneos.
} 
Pesquisas realizadas, nos últimos anos, nas áreas das Ciências Humanas e Sociais constataram o grande potencial de mobilização que pode ser atribuído ao Facebook e outras ferramentas de sociabilidade virtuais enquanto plataforma de articulação a partir de pautas (políticas, sociais, culturais, entre outras), tanto no sentido da democratização, quanto da desdemocratizaçáo da sociedade. Assim, se por um lado o acesso em massa às redes de comunicaçóes digitais viabilizou a ascensão de formas estratégicas de pressóes progressistas no espaço político (SAMPAIO, 2010; CUNHA; 2017), por outro também favoreceu uma crescente polarização dos grupos em disputa, apresentandotendência ao fortalecimento de grupos antidemocráticos (AVRITZER, 2018; HANSEN; FERREIRA, 2018).

Além das potencialidades políticas democráticas ou antidemocráticas destas plataformas digitais, é necessário, também, atentar-se as implicaçôes de suas configuraçôes concretas para o ser social inserido na atual conjuntura do estado de coisas. Mais especificamente, busca-se apreender como esta plataforma virtual, que pressupóe a integração entre sujeitos e ideias, insere-se no âmbito da alienação do complexo ideológico contemporâneo. Dentro desta perspectiva, não se pode deixar de problematizar "que a superação prática da alienação é inconcebível em termos exclusivamente políticos, tendo em vista o fato de que a política é apenas um aspecto parcial da totalidade dos processos sociais, por mais importante que possa ser em situaçóes históricas específicas [...]” (MÉSZÁROS, 2006, p. 91).

A grande questão que se coloca, no âmbito ontológico, sobre as dimensóes assumidas na configuração atual desta plataforma é que ela possibilita a ascensão de espaços de encastelamento para as distintas concepçóes de mundo que caracterizam a dinâmica das disputas ideológicas nas sociedades capitalistas. Uma das principais ferramentas, aperfeiçoadas pela FacebookInc. para viabilizar determinado fenômeno são os algoritmos, mecanismo que por intermédio das reaçóes dos usuários a determinados conteúdos elenca as informaçóes de maior ou menor relevância para cada integrante da rede social (PARISIER, 2012) - o mecanismo é utilizado tanto no Facebook quanto no Instagram.

Além da classificação pela reação do sujeito ao conteúdo, os usuários da plataforma podem também indicar por conta própria o grau de interesse em determinadas páginas e perfis, o que implica na viabilidade de gradualmente impedir a apresentação de sugestóes de contatos, grupos e informaçôes divergentes dos gostos ou convicçóes no feed de notícias do usuário, sob o pretexto de personalizar esta página de acordo com o perfil de cada indivíduo (CARLSEN; BIRKBAK, 2017).

Deste modo, inseridos no Facebook, os sujeitos singulares contemporâneos esbarram-se com a possibilidade de se refugiar em espaços de debates exclusivamente concomitantes com suas formas de apreensão da realidade, não só as limitando como favorecendo uma crescente distorção e fragmentaçáo da totalidade da vida social. Em outras palavras, estes espaços virtuais podem tornar-se territórios de predomínio quase absoluto de concepçóes de mundo específicas, viabilizando um rompimento dos sujeitos singulares com os demais elementos da realidade concreta (entendida como síntese de múltiplas determinaçóes). Nesta perspectiva, "[...] a alienação de cada ser humano singular brota imediatamente de suas interaçôes com sua própria vida cotidiana” (LUKÁCS, 2018b, p. 556).

Dentro desta problemática, é relevante atentar-se a duas formas de construção do pensamento humano historicamente formuladas e aperfeiçoadas que caracterizam as configuraçóes contemporâneas das posiçóes teleológicas secundárias: o irracionalismo (LUKÁCS, 2020) e a razão miserável (COUTINHO, 2010). Enquanto o irracionalismo parte do princípio de romper completamente com as cadeias lógicas de construção cartesiana da reflexividade, centrando-se nas convicçóes 
exclusivamente individualistas do sujeito singular (LUKÁCS, 2020), a razão miserável apropria-se de elementos fragmentados da realidade, por vezes os distorcendo, para a construção de uma lógica reflexiva que atribua validade às concepçôes de mundo partilhadas por determinados grupos sociais (COUTINHO, 2010).

Farias, Cardoso e Oliveira (2020) demonstram a forma como esses espaços digitais contemporâneos, como Facebook, favorecem, inicialmente, a proliferação dos princípios de pós-verdade e, em seguida, a massiva difusão das fake news. ${ }^{11}$ Assim, tanto no âmbito das perspectivas conservadoras, quanto das progressistas, as tendências alienantes do ser social podem ser aprofundadas nos parâmetros de socialização dos espaços virtuais consolidados pelo Facebook. Se, por um lado, esta plataforma disponibiliza aos grupos detentores de concepçôes de mundo menos complexas e a viabilidade de reforçar o irracionalismo, desatribuindo os sujeitos que partilham de seus pressupostos de enfrentarem concepçóes divergentes de mundo, por outro, também favorece que grupos defensores de percepçóes mais complexas da vida social, inclusive progressistas, apreendam a realidade de forma cada vez mais fragmentada e imprecisa.

No caso do fenômeno contemporâneo de ampla difusão das fake news, por exemplo, as posiçóes teleológicas secundárias irracionalistas vislumbraram a possibilidadede validar, ao menos para si e para seus pares, suas convicçóes e juízos de valores (por mais distorcidos e nocivos para a realidade que o sejam $)^{12}$ - o inicial negacionismo da pandemia Covid-19, a refutação da eficácia das vacinas e outras formas decontestação de evidências científicas servem para ilustrar as implicaçôes contemporâneas deste aspecto das redes sociais. Já o caso da razão miserável se torna um pouco mais delicada, contudo, é possível indicar que, em determinada medida, as efetivas e massivas conquistas políticas e econômicas consolidadas por grupos antidemocráticos na última década (2011-2021) devem-se, entre outros aspectos, ao encastelamento de grupos progressistas que, inseridos em bolhas de pares, recusaram-se a reconhecer o caráter volátil dos Estados democráticos.

Apesar de haver se consolidado como um dos maiores espaços de reprodução da pós-verdade que ameaçam não só a manutenção das ordens democráticas internacionais, a FacebookInc. tem demostrado publicamente interesse e esforços para romper com essa distorcida apropriação de suas ferramentas na contemporaneidade. Também é relevante considerar que a plataforma ainda se consolida como espaço de difusão das mais diversas perspectivas políticas e ideológicas ${ }^{13}$ - inclusive, este próprio artigo, que critica os efeitos nocivos das ferramentas da FacebookInc., pode se apropriar destas mesmas plataformas para ser publicizado e difundido. Assim, retomando os aspectos alienantes do ser social na contemporaneidade, é impossível inferir que, nolongo prazo, o Facebook não possa vir a se consolidar como uma das múltiplas ferramentas necessárias para a conquista da superação das tendências alienantes do ser e do subsequente processo de emancipação humana.

Por outro lado, não se deve deixar de explicitar que durante sua década e meia de existência, o Facebook engendrou processos de aprimoramento, passando não só a possibilitar a interação com outras redes sociais, como também, ainda mais relevante, integrar mecanismos de propulsão

11 Reconhecendo a existência de divergências no âmbito da definiçáo do que se caracteriza efetivamente como fake news, Kalsnes (2018) indica que o fenômeno comumente se distingue pela vinculação com estratégias de mobilização sociais, políticas ou financeiras.

12 Apesar de não deixar de reconhecer o papel essencial exercido pelo WhatsApp neste processo, o trabalho enfatiza a inviabilidade de adentrar esta problemática no presente momento, reservando o interesse de dar continuidade a esta discussáo em produçóes posteriores.

13 Sem deixar de indicar que, no plano concreto da conjuntura contemporânea, oFacebook e outras ferramentas digitais vêm sendo apropriadas pelos serviços de inteligência estado-unidenses para a realizaçáo das chamadas Revoluçóes Coloridas em países da antiga Uniáo Soviética, de modo a atender os interesses hegemônicos do capital internacional (KORYBKO, 2018). 
de propagandas comerciais de grandes e pequenas empresas de produtos e serviços que também se fundamentam no princípio de algoritmos (SRNICEK, 2017). Especialmente, essa apropriação da rede social para a reprodução da lógica de consumo expressa outro dos elementos alienantes do Facebook.

Os mecanismos de identificação inteligente de interesses por algoritmos não é uma exclusividade doFacebook, poisperpassam amplamente a interação dos sujeitos singulares inseridos nas plataformas virtuais contemporâneas, direcionando produtos e conteúdos que estáo adequados às vontades e preferências em potencial dos usuários. No esquema cotidiano da vida social, o objetivo de determinados mecanismos é amplificar nos sujeitos singulares a percepçáo da necessidade urgente de consumo dos produtos e serviços apresentados.

Assim, o acúmulo de bens materiais (por vezes fúteis e, quase sempre, irrelevantes) torna-se um imperativo determinante no direcionamento das açóes cotidianas dos sujeitos singulares, que passam a adequar-se aos padróes de produção que os subjugam em prol da obtenção de bens dos quais não necessitam.Estes espaços digitais, nos quais os mecanismos de direcionamento de propaganda por algoritmos se desenvolvem, constituem locais extremamente dinâmicos para o aprofundamento das tendências alienantes do ser social. Enfatiza-se, contudo, que apesar de se estender para outras plataformas virtuais (como Google e Facebook), este fenômeno evidencia-se de forma muito mais expressiva no Instagram. Deste modo, torna-se relevante estender nossas análises para este outro componente do conglomerado FacebookInc.

\section{O CASO DO INSTAGRAM}

Lançado no ano de 2010, o Instagram foi criado por Kevin Systrom e Mike Krieger, sendo posteriormente adquirido pelo grupo FacebookInc. no ano de 2012, tendo como proposta disponibilizar uma plataforma diferenciada para o compartilhamento de fotos de seus usuários, apresentando filtros e mecanismos para o tratamento das imagens. Atualmente, a rede social conta com mais de umbilhão de usuários ativos, destacando-se enquanto uma das principais plataformas do FacebookInc. Com o seu processo de aperfeiçoamento, a plataforma passou a possibilitar o compartilhamento de vídeos, ao mesmo tempo em que se apropriou das ferramentas de algoritmos para identificação inteligentede interesses dos usuários buscando não só direcionar as mencionadas propagandas de produtos e serviços, como também indicar perfis e conteúdo interno concomitante com as últimas pesquisas e reaçóes do usuário.

Conforme indicou-se no tópico anterior, estes mecanismos de direcionamento de propaganda por algoritmos exercem um papel primordial no processo de fomento das demandas de consumoexacerbado em meio à conjuntura contemporânea. $\mathrm{O}$ objetivo de reproduzir e induzir, nos sujeitos singulares, a sensação de necessidade de consumo dos produtos e mercadorias encontra, nas plataformas digitais, vias de difusão amplamente ágil e de baixos custos (quando comparado com os veículos de propaganda do período de hegemonia da mídia de massa). Dentro desta perspectiva, enfatiza-se que, dentro da plataforma Instagram, estas ferramentas assumem uma forma extremamente dinâmica, quando comparada às congêneres (como Facebook).

Assim, é interessante atentar-se ao fato de que o Instagram apropria-se de um mecanismo de direcionamento de conteúdo por algoritmos que inunda o visor do usuário com vídeos e imagens que potencialmente podem interessá-lo. Este mecanismo exerce uma dupla função: em primeiro lugar, a da difusão de propagandas voltadas para fomento do consumismo exacerbado; em segundo, para garantir a ampliação do tempo despendido pelo sujeito na plataforma. Em decorrência destas 
especificidades, todo o conteúdo veiculado na plataforma torna-se uma mercadoria em potencial, desde os efetivos produtos e serviços oferecidos, até os supostos estilos de vida escolhidos pelos usuários. Determinada particularidade gera fenômenos e efeitos específicos que decorrem diretamente das dimensóes que este espaço da vida social assume em relação ao ser na contemporaneidade.

Destaca-se, em um primeiro momento, a reformulaçáo de valores preconizados e difundidos por consequência da ascensão do Instagram enquanto rede de interação social. Os inúmeros filtros e ferramentas disponibilizados por esta plataforma digital cristalizaram, em meio a uma multiplicidade de sujeitos singulares, o desejo de atingir padrôes estéticos corporais incondizentes com a natureza da própria espécie humana. Estes valores recém consolidados, é claro, abastecem distintos mercados de produtos e serviços (desde vestimentas e produtos de beleza, até as efetivas intervençóes cirúrgicas para transformação das características naturais do sujeito). ${ }^{14}$ Não se defende, obviamente, que este fenômeno é uma especificidade decorrente do Instagram; pelo contrário, se reconhece que a busca pela transformação das características naturais do sujeito singular para se adequar a padróes de beleza hegemônicos de uma época é um elemento que se constrói de forma social, cultural e histórica. Neste sentido, inclusive, torna-se relevante considerar que:

[...] valores surgem apenas através da exteriorização-objetivação; a simples objetividade é, por princípio, indiferente ao valor; apenas na medida em que, de algum modo, é incorporada ao sistema das objetivaçóes-exteriorizaçóes pode conter um valor, p. ex., quando uma porção de natureza se torna uma paisagem para os seres humanos. Que este ser-posto tem sua base nos reais momentos objetivos da porção de natureza concernente, compreendeu-se por si próprio; nâo supera, todavia, este estado de fato: altas montanhas estavam por longo tempo dadas antes que um determinado desenvolvimento humano as tivesse feito uma paisagem em sentido social. Seria, todavia, de todo equivocado enxergar, agora, nesses próprios atos de posição algo de valoroso. Eles são simples momentos de ser do ser social e podem, por isso, igualmente, ser valoroso ou avesso-ao-valor, são, portanto, de modo necessário, vinculados a um tornar-se consciente cujo desfecho depende do seu concreto ser-precisamente-assim e não toca seu caráter ontológico - no interior do ser social -, pode-se mesmo dizer: apenas porque cada exteriorização-objetivação constitui em si um componente do ser social, desencadeia de modo necessário, simultaneamente com seu tornar-se existente, valores e, na sua consequência, avaliações (LUKÁCS, 2018b, p. 361).

A questão que se coloca, portanto, é apreender as especificidades que estes valores assumem em decorrência da inserção do ser social na rede virtuallnstagram. Assim, busca-se problematizar que no atual estado de coisas, possibilitado pelo bombardeamento de conteúdo "de interesse" dos sujeitos singulares, os valores estéticos, especialmente corporais, assumem dimensóes gigantescas no cotidiano da vida do sujeito singular, fomentando fanatismos e obsessóes pela perseguição de uma imagem de ser que, no âmbito da realidade concreta, pode ser construída ou mantida apenas com a aplicação de inúmeros filtros e ferramentas de modificação de imagens. Sem ambicionar prolongar

$14 \quad$ Apesar de reconhecer o rico potencial de uma análise das transformaçôes de valores estéticos consolidados pelas redes sociais virtuais contemporâneas à luz das contribuiçôes de Lukács para a temática, é necessário reconhecer os limites cabíveis à proposta aqui apresentada. 
as discussôes no campo da estética, é possível retomar neste ponto as implicaçôes deste fenômeno para o âmbito das tendências alienantes do ser social.

Conforme indicou-se anteriormente, a alienação é o elemento da vida social mais decididamente centrado no indivíduo, seu objetivo é deslocar o sujeito singular do âmbito social, isolar os indivíduos para enfraquecer a classe e prevenir possíveis articulaçóes sociais que objetivem a superação da ordem de dominação. Dentro desta perspectiva, torna-se necessário enfatizar que o Instagram, atualmente, pode ser considerado como uma das mais bem aprimoradas ferramentas do aparato capitalista para a exaltação da individualidade. As formas como os distintos sujeitos singulares tendem a interagir nesta plataforma em específico constituem-se praticamente como verdadeiras odes às pretensas particularidades da individualidade. ${ }^{15}$ Assim, inserido na plataforma Instagram, o sujeito singular apresenta fortes tendências a isolar-se do seu âmbito social, especialmente quando se levaem consideração a totalidade da dimensão social do ser, alienando-ado mundo exterior que perpassa a concretude de sua efetiva realidade. Dentro desta questão, é forçoso indicar que:

Também aqui repetimos que a alienaçáo nunca deve ser considerada como um fenômeno independente ou mesmo imediato, ontologicamente central, na vida dos seres humanos. Ela cresceu, sob todas as circunstâncias a partir da estrutura econômica como um todo da respectiva sociedade, confundindo-se com ela, jamais é separável do patamar de desenvolvimento das forças produtivas, do nível das relaçôes de produção (LUKÁCS, 2018b, p. 663).

Em outras palavras, o caráter específico que a alienação assume no Instagram relaciona-se diretamente com o atual estágio de produção da humanidade, assim como das condiçóes materiais que caracterizam a totalidade do complexo de complexos da divisão internacional do trabalho. Assim, é justamente em decorrência dos aspectos virtuais que o trabalho pode apresentar na sociedade dos serviços e do empreendedorismo, que esta plataforma digital obtém tamanho sucesso na reprodução e aprofundamento das tendências alienantes do ser social. ${ }^{16}$ Outro elemento do empreendedorismo, amplamente vendido e difundido na sociedade contemporânea, é o da obtenção de riquezas por meio do trabalho imaterial, a exemplo de profissões hoje denominadas como "youtubers", "instagramers", entre outros.

A partir da ascensão de inúmeros casos de sujeitos singulares que obtiveram êxito na escalada econômica e social a partir da mera veiculação de suas imagens e, por vezes, pontos de vista (por mais descompromissados com os fatos ou com a própria realidade em si) cristalizou-se em meio à sociedade civil contemporânea a valorização destes métodos imateriais de garantia da subsistência sem que se problematize, ao menos de forma complexa, a insustentabilidade de manutenção destes setores de trabalho que não contribuem para o processo de produção e reprodução do capital em sentido concreto e que, portanto, servem apenas como ilusôes fátuas, fadadas à obsolescência.

\footnotetext{
15 Em concordância com a corrente teórica que a fundamenta, esta pesquisa compartilha do reconhecimento da existência de elementos únicos que tornam os sujeitos sociais singulares, mas, ao mesmo tempo, afirma a impossibilidade de conceber um sujeito como emancipado de uma conjuntura social.Todas as características que tornaram este sujeito singular em relação aos demais foram condicionadas por elementos conjunturais de sua realidade concreta (LUKÁCS, 2018a; 2018b).

16 Conforme demonstra Antunes (2018) o trabalho assume formas muito ímpares na conjuntura contemporânea do capitalismo, especialmente quando se considera a revitalização e difusão da perspectiva de empreendedor autônomo, que adentra o campo da prestação de serviços com a falsa percepçáo de autogestão do próprio trabalho, submetendo-se a condiçóes paupérrimas e retrógradas dos direitos trabalhistas.
} 
Em grande medida, as condiçôes para o sucesso de um perfil no território virtual do Instagram residem na exposição de um estilo de vida que representa gostos e interesses de parcelas da população, exposição esta que deve fundamentar-se em padróes irreais de beleza, riqueza e outros elementos que compóem a materialidade da vida social. Em outras palavras, as formas como a vida destes sujeitos singulares é exposta na plataforma, não condiz com a realidade efetiva na qual se encontram inseridos: estão fragmentos do cotidiano e são, assim, moldados e reformulados a partir dos interesses e anseios do sujeito singular para serem expostos ao mundo virtual como a realidade que o sujeito construiu para si no plano de idealização.

Deste modo, indica-se que o Instagram consolida-se enquanto um espaço virtual no qual os sujeitos singulares vislumbram a possibilidade de se refugiar dos problemas inerentes à sua condição de subalternidade na dinâmica da divisão do trabalho na sociedade capitalista, moldando, ficcionalmente, realidades alternativas de existência que não condizem com as condiçóes materiais a eles impostas. Em sentido ontológico, determinado fenômeno compele o indivíduo a alienar-se cada vez mais das efetivas relaçóes concretas da vida social, rompendo com as possibilidades de tomada de consciência de classe, o que a longo prazo viabilizaria um efetivo processo de emancipação das relaçôes de dominação.

Isto nos leva a problematizar que "todas as manipulaçôes econômicas, sociais e políticas dominantes tornam-se, com isso, instrumentos mais ou menos conscientes para acorrentar o ser humano a sua particularidade e, com isso, ao seu ser alienado" (LUKÁCS, 2018b, p. 700). Deste modo, estes sujeitos singulares devem ser considerados como vítimas e, ao mesmo tempo,como reprodutores desta distorcida lógica de auto resignaçáo e de aprofundamento das tendências alienantes do ser social que prolifera e difunde-se nas plataformas digitais - com ênfase para o Instagram.

\section{CONSIDERAÇÕES FINAIS}

Este trabalho teve como proposta problematizar as potenciais implicaçôes ontológicas que o aprimoramento e difusão das redes sociais virtuais Facebook e Instagram exercem na vida social contemporânea. Mais especificamente, buscou-se apreender, a partir da perspectiva ontológica lukácsiana, como estas plataformas de relacionamento digitais atuam no sentido de aprofundar as tendências alienantes do ser social.

No que tange ao Facebook, indicou-se a dualidade que coexiste no espaço virtual consolidado pela plataforma. Por um lado, concretamente esta rede social vem demonstrando constituir-se enquanto local de fragmentação e isolamentos dos grupos de classe a partir de concepçôes concomitantes de mundo que distanciam os sujeitos singulares da totalidade da vida social, favorecendo a cristalização de posiçóes teleológicas secundárias que se embasam nos princípios do irracionalismo ou da razão miserável e, por consequência, contribuindo para o aprofundamento das tendências alienantes do ser social. Por outro lado, apesar da problemática do direcionamento e do controle de conteúdo por algoritmos e do caráter privado da plataforma, existem pressupostos democráticos que caracterizam este espaço digital eatribuem um relativo potencial de mobilizaçáo e articulaçáo popular a partir da unificação de pautas, o que direciona a considerar o Facebook como uma das possíveis ferramentas necessárias à incorporação para a difusão de uma concepção de mundo emancipadora das relaçôes de dominação contemporâneas.

O Instagram, por sua vez, foi apresentado como uma das mais aperfeiçoadas ferramentas de alienação desenvolvidas pelo capitalismo. O território virtual consolidado por esta plataforma fundamenta-se em princípios de exaltação da individualidade e distorção da realidade concreta imposta aos sujeitos singulares no cotidiano da vida social. São diversos os aspectos nocivos desta 
plataforma para o ser social, desde a busca por padróes irreais de beleza até o completo afastamento do sujeito singular das capacidades de apreender e enfrentar os problemas concretos de sua realidade. Inseridos nesta plataforma específica, os sujeitos singulares encontram, assim, a possibilidade de expor virtualmente um estilo de vida que não seja condizente com suas efetivas condiçóes materiais, deturpando assim não só a sua própria realidade como, também, favorecendo a cristalização do consenso da ideologia única e da resignação do ser social às condiçôes de dominação impostas.

Não se deve deixar de evidenciar, também, a forma como as duas plataformas da FacebookInc. são incorporadas pela lógica do mercado capitalista, sendo utilizadas como ferramentas de difusão do consumismo exacerbado, favorecendo métodos ágeis e dinâmicos para a criação de necessidades em meio aos sujeitos singulares cada vez mais distantes das efetivas demandas de subsistência do gênero humano. No âmbito da alienação, este processo contribuí ideologicamente para que os sujeitos sociais se resignem aos mais absurdos padróes de exploração da força de trabalho, desde que a remuneração possibilite saciar os desejos que se difundem.

Por fim, é necessário enfatizar que as problematizaçóes expostas neste artigo perpassam um processo reflexivo inicial de um fenômeno recente que se transforma de modo dinâmico. Deste modo, reforça-se o caráter qualitativo das análises aqui expostas e indica-se que, muito distante de pretender esgotar as discussóes sobre esta temática, o presente trabalho objetivou incitar a construção de novas pesquisas sobre estes objetos de análise que têm demonstrado grande capacidade de interferir no cotidiano da vida social contemporânea.

\section{REFERÊNCIAS}

ANTUNES, Ricardo. O Privilégio da Servidáo. São Paulo: Boitempo, 2018.

AVRITZER, Leonardo. O pêndulo da democracia no Brasil: uma análise da crise 2013-2018. Novos estudos CEBRAP, São Paulo, vol. 37 n. 2, p. 273-289, 2018.

CARLSEN, Hjalmar A. B.; BIRKBAK, Andreas. The world of Edgerank: rethorical justifications of Facebook's news feed algorithm. Computational Culture, Copenhagen, vol. 5, 2016.Disponível em: https://static-curis.ku.dk/portal/files/185069826/Computational Culture.pdf. Acesso em: 12 fev. 2021.

CASTELLS, Manuel. O Poder da Comunicaçáo. 2a ed. Rio de Janeiro/São Paulo: Paz e Terra, 2017.

CHASIN. José. O Integralismo de Plínio Salgado: forma de regressividade no capitalismo hipertardio. São Paulo: Livraria Editora de Ciências Humanas, 1978.

COUTINHO, Carlos Nelson. O Estruturalismo e a Miséria da Razão. 2a ed. São Paulo: Expressão Popular, 2010.

CUNHA, Magali. Política, mídia e religião: o ativismo progressista entre evangélicos brasileiros por meio do Facebook e do Twitter. Comunicaçáo \& Sociedade, São Bernardo do Campo, vol. 39, n. 3, p. 217-244, 2017.

EISENBERG, José. Internet, Democracia e República. Dados - Revista de Ciências

Sociais, Rio de Janeiro, vol. 46, n. 3, p. 491-511, 2003.

FACEBOOK. Facebook Reports First Quarter 2020 Results. California, 2020. Disponível em: https://investor.fb.com/investor-news/press-release-details/2020/Facebook-Reports-First-Quarter2020-Results/default.aspx. Acesso em: 15 fev. 2021. 
FARIAS, Luiz A. de; CARDOSO, Ivelise; OLIVEIRA, Paulo R. N. de. Comunicação, opinião pública e os impactos da revoluçáo digital na era da pós-verdade e Fake News. Organicom, Sáo Paulo, ano 17, n. 34, p. 71-81, 2020.

HANSEN, Jaqueline R; FERREIRA, Maria A. S. Da polarização à busca pelo equilíbrio: as relações entre internet e participação política. Revista Eletrônica de Ciência Política, Curitiba, vol. 9, n. 1, p. 5-20, 2018.

KALSNES. Bente. Fake News. In: Oxford Research Encyclopedia of Communication, Oxford, p. 01-24, set. 2018.

KORYBKO, Andrew. Guerras Híbridas: das revoluçóes coloridas aos golpes. São Paulo: Expressão Popular, 2018.

LESSA, Sérgio. Nota da Tradução. In: LUKÁCS, Georg. Aparato Crítico 2018: obras de Georg Lukács volumes 13 e 14. Maceió: Coletivo Veredas, 2018.

LIMA, Francisco Renato. Fake news e campanhas de vacinaçáo: a experiência com projetos de intervenção pedagógica na Educação Básica. São Carlos: Pedro \& João Editores, 2019

LOVATTO, Angélica. Os Cadernos do povo brasileiro e o debate nacionalista nos anos 1960: um projeto de revoluçâo brasileira. Tese (Doutorado em Ciências Sociais). Pontifícia Universidade Católica, São Paulo, 2010.

LUKÁCS, Georg. Introduçáo a uma estética marxista: sobre a particularidade como categoria estética. $2^{a}$ ed. Rio de Janeiro: Civilização Brasileira, 1970.

. Prolegômenos e Para a ontologia do ser social. Volume 13. Maceió: Coletivo Veredas, 2018a.

Para a ontologia do ser social. volume 14. Maceió: Coletivo Veredas, $2018 \mathrm{~b}$.

A destruição da razão. São Paulo: Instituto Lukács, 2020.

MARX, K; ENGELS, F. A Ideologia Alemá: crítica da mais recente filosofia alemã e seus representantes Feuerbach, B. Bauer e Stirner, e do socialismo alemão em seus diferentes profetas (1845-1846). São Paulo: Boitempo Editorial, 2007.

MARX, Karl. Contribuição à Crítica da Economia Política. 2a ed. São Paulo: Expressão Popular, 2008.

O Capital: Livro I. 2a ed. São Paulo: Boitempo Editorial, 2011.

MÉSZÁROS, István. A teoria da alienação em Marx. São Paulo: Boitempo Editorial, 2006.

O poder da ideologia. São Paulo: Boitempo Editorial, 2014. 
PARISER, Eli. O filtro Invisível: O que a internet está escondendo de você. Rio de Janeiro: Zahar, 2012.

SAMPAIO, Rafael C. Participação política e os potenciais democráticos da internet. Revista Debates, Porto Alegre, vol. 4, n. 1, p. 29-53, 2010.

SRNICEK, Nick. Platform Capitalism. Polity Press: Cambridge, 2017.

VAISMAN, Ester. A ideologia e sua determinação ontológica. Verinotio revista online, Belo Horizonte, n. 12, ano VI, p. 40-64, outubro de 2010. 